\title{
BIOÉTICA, DERECHO A LA SALUD Y VIRTUDES JUDICIALES: DILEMAS E INTERROGANTES GIRATORIAS SOBRE EL COVID-19
}

\author{
BIOETHICS, THE RIGHT TO HEALTH AND JUDICIAL \\ VIRTUES: DILEMMAS AND REVOLVING QUESTIONS \\ ABOUT COVID-19
}

Ramsés Samael Montoya Camarena'

DOI: https://doi.org/10.37767/2591-3476(2020)19

Fecha de envío: 17.08.2020

Fecha de aceptación: 08.09.2020

\section{RESUMEN:}

El texto tiene un triple propósito. Primero busca establecer que el principio de imparcialidad rawlsiano es rector en materia bioética y está relacionado con el modelo de las virtudes judiciales. En el segundo punto se describen los principios bioéticos que imperan en el derecho a la salud frente a casos de escasez de recursos. Finalmente, se presentan algunas interrogantes que a modo de diálogo abierto, nos llevan a dilemas inconclusos, susceptibles de razonar desde la ponderación de principios bioéticos y su relación con las emociones virtuosas en escenarios de judicialización del derecho a la salud y escasez de recursos a causa del COVID-19.

\begin{abstract}
The text has a triple purpose. First, it seeks to establish that the rawlsian principle of impartiality is guiding in bioethics and is related to the model of judicial virtues. The second point describes the bioethical principles that prevail in the right to health in cases of scarcity of resources. Finally, some questions are presented that, by way of open dialogue, lead us to unfinished dilemmas, capable of reasoning from the weighting of bioethical principles and their relationship with virtuous emotions in scenarios of judicialization of the right to health and limited resources to provide it to cause of COVID-19.
\end{abstract}

PALABRAS CLAVE: bioética, imparcialidad, virtudes judiciales.

KEY WORDS: bioética, impartiality, judicial virtues. 


\section{Introducción.}

Todo Estado constitucional defiende fines y valores. Los bienes valiosos que persigue el Estado constitucional son propios de las sociedades democráticas. La característica principal de la democracia se remonta a la pluralidad e igualdad de trato. La democracia y la situación demográfica demuestran que debido al crecimiento poblacional, aumentan las demandas de bienes y servicios en el sector público. El problema sienta sus bases en la escasez de recursos para satisfacer la creciente demanda de esos bienes de valor incomensurable.

El problema es más visible cuando la escasez de recursos impide que se garantice la igualdad de trato en la protección del derecho a la salud porque su acceso se encuentra condicionado por la disponibilidad de recursos para su satisfacción.

La escasez de recursos se debe a múltiples factores impulsados por el adelgazamiento del proyecto social democráta motivado por el pragmatismo libertario eficientista donde los fenómenos económicos del libre mercado como son: la concentración de riqueza, la privatización de servicios públicos, la defensa de un Estado mínimo como agente regulador, la idea de tecnocrácia acompañada de una cultura empresarial y directices competitivas de normalización social; han influido de forma determinante en que con esos cambios estructurales la oferta mundial de ciertos producos sea inelástica y, el acceso a los recursos disminuya (Vázquez, 2019: 114).

La pandemia global causada por el COVID-19 ha traído a nuestras vidas interrogantes muy díficiles de responder. En muchas de ellas, los dilemas morales desde la bioética, no parecen admitir una respuesta definitiva. Los tribunales han tenido que enfrentarse a algunas. Aquí nos ocuparemos de algunas preguntas que representan dilemas inconclusos que toca fibras del modelo judicial al que se puede aspirar. El método empleado en el texto es el deductivo y el crítico dialógico porque se plantean principios generales para resolver casos particulares que sugieren la ponderación de estos, según cada circunstancia y sus particularidades.

\section{Bioética, imparcialidad y virtudes judiciales}

Haremos un breve recorrido para identificar cómo y en dónde se conecta la bioética con el principio de imparcialidad rawlsiano y las virtudes judiciales. La idea de que a los problemas existen respuestas correctas y definitivas surge como una apelación ideal de la racionalidad. Se encuentra en el espectador imparcial de Adam Smith; el juez Hércules de Dworkin, el auditorio universal de Perelman o la comunidad ideal de diálogo de Habermas. Sin embargo, los dilemas morales que presenta la bioética, parecen encontrarse en la franja fronteriza de esa idealización de corrección moral.

Lo que busca la respuesta correcta, por ejemplo, desde la posición intermedia de Alexy, explica Atienza, consiste en una idea regulativa de la argumentación donde el operador ha llegado a la convicción de que es la única respuesta. La idea de la respuesta correcta se enfrenta a discernir sobre los medios para alcanzar los fines últimos. Por lo que se trata de una racionalidad instrumental y una racionalidad ética, donde no se pretenden juicios absolutos sobre los fines últimos.

Ante las dificultades de encontrar una decisión correcta en casos díficiles es necesario apostar por las virtudes de racionalidad práctica, dice Atienza y, también otras cualidades 
como las propuestas por MacCormick, entre ellas: buen juicio, perspicacia, prudencia, altura de miras, sentido de justicia, humanidad, compasión o valentía. Es acompañar la teoría de la razón práctica con una teoría de las pasiones.

Atienza aclara que razón y pasión no es igual que el agua y el aceite; es decir, el mundo de las emociones no es simplemente el mundo de lo irracional. Las emociones, por el contrario, parecen guardar cierto tipo de relación interna con la razón. Por un lado, la razón no podría funcionar sin pasión, por lo que de ejemplo se toma a Hume en el dictum "la razón es esclava de las pasiones" por lo que la razón no se mueve por sí misma; no es un fin en sí misma, sino un medio para la satisfacción y ordenación de deseos y necesidades. Todos parecen aceptar que las emociones están sometidas a algún parámetro de racionalidad; incluso por ello algunas se califican de razonables o irrazonables. Entonces, dice Atienza, las pasiones, las buenas pasiones, parecen ser la mejor guía para la razón (Atienza, 2012: 136-141).

Una buena ruta para lo anterior es lo que propone Nino, a través de lo "segundo mejor", donde se propone que en el caso concreto el decisor opte por la decisión más óptima de las posibles mejores soluciones en abstracto, al comprender que la determinación de un operador no está aislada, sino que forma parte de un global social que habrá de imbrincarse e integrarse con otras acciones y decisiones constitutivas del orden constitucional (Nino, 1980: 66 y 67).

Por otra parte, el principio de imparcialidad defendido por Rawls parte del liberalismo igualitario secularizado, al señalar los problemas de los libertarios que piensan que la autonomía de las personas se distribuye espontáneamente, en una ilusión donde el contexto parece no importar y en el rechazo de que el liberalismo pueda fincarse en un perfeccionamiento moral construido desde sistemas de vida aceptables.

Detrás de ese principio, se encuentra una versión del neocontractualismo, en donde el acuerdo voluntario construido por las personas no impera por razones de poder, estatus social o cuestiones de privilegio y, además, se orienta hacia una protección prioritaria de los más vulnerables por desigualdades provocadas arbitrariamente, pero que merecen ser corregidas.

Cada persona debe ser comprendida independiente en sus elecciones y decisiones. Por lo que el principio de imparcialidad apunta a un enfoque de solidaridad colectiva que no acepta el individualismo atomista ni la tesis de sacrificio costo-beneficio que defiende el utilitarismo. Al contrario, la imparcialidad surge, desde la teoría de la elección racional, en un marco de cooperación y acuerdos respetuosos de las libertades, con racionalidad y auto-interés en obtener lo mejor en la peor situación a través de la llamada regla maximin.

El principio de imparcialidad se logra también mediante un juicio reflexivo donde haya un movimiento dinámico de los principios de igualdad y libertad en condiciones razonables. En ellos, el principio de diferencia señala que si en la asignación de recursos una situación es superior a otra, porque una persona está mejor que otra y no existe otra en peor situación; entonces, se justifica la desigualdad real entre los invidividuos siempre que se estructuren en beneficio de los menos aventajados; este principio también hace aceptable lo inverso cuando los más aventajados mejoren la situación de los más necesitados o vulnerables (Rawls, 2004: 17-118). 
El Estado, desde este eje, debe distribuir en forma equitativa el acceso a los bienes básicos, en términos progresivos, en tanto deber positivo de acción con el que se procura la justicia dentro de una sociedad plural. Entonces, el Estado debe afrontar la escasez de recursos con medidas presupuestarias suficientes $y$, en ese sentido, priorizar aquellos escenarios donde haya mayor fragilidad en el acceso a esos bienes básicos.

Dice Vázquez que este tipo de liberalismo se compromete con una defensa de los derechos humanos, entendidos no solo como derechos negativos, protegidos por un Estado mínimo y gendarme, sino que amplía el horizonte de su comprensión hacia la satisfacción de bienes primarios con una decidida intervención del Estado para su protección y garantía (Vázquez, 2019: 29-56).

Es de interés para la bioética, esta mancuerna de libertad e igualdad, desde la solidaridad con los más necesitados, con la intención de proteger el bien primario de la salud. Además, debe tenerse en cuenta que los principios bioéticos, para Beauchamp y Childress, son prima facie y no absolutos, por lo que obligan siempre y cuando no entren en conflicto entre sí y, si existe un conflicto, entonces, deben jerarquizarse en casos concretos, según cada contexto (Beaucham y Childress, 1979: 7-13).

La vía sugerida apuesta por una aproximación hermenéutica, dialéctica y crítica al caso concreto, para evitar el conservadurismo moral. Atienza, en ese sentido, propone la idea de ponderar entre los principios en conflicto desde la igualdad de trato y reconociendo el mérito del trato diferente, cuando sea necesario.

Este principio de trato diferenciado indica lo siguiente: Es lícito tratar a una persona de manera distinta que otra si: a) la diferencia de trato se basa en una circunstancia que sea universalizable; b) produce un beneficio apreciable en otras $u$ otras $y, c$ ) se puede presumir racionalmente que el perjudicado consentiría si pudiera decidir en circunstancias de imparcialidad (Atienza, 1999: 83-86).

Así, los dilemas morales en la bioética aplicada al caso deben pasar por un examen social, activo, imparcial, universal, racional y transparente. Cualquier decisión sobre los límites éticos debe tener de fuente, los intereses de todas las personas, desde una ética mínima, en términos de Adela Cortina, para nivelar también las cuestiones fácticas de desventaja (Cortina, 2010: 130-138) y, cuando estos problemas se llevan al terreno de los tribunales, las decisiones deben acompañarse de un modelo de virtudes judiciales porque los casos están sujetos a una concepción de racionalidad universal que debe inspirar confianza al corregir la escasez de recursos causada por desigualdades provocadas arbitrariamente.

\section{Derecho a la protección de la salud y principios bioéticos}

En México, la Suprema Corte de Justicia de la Nación ha emitido diversos criterios de protección del derecho a la salud buscando que el Estado lo garantice tanto en su dimensión individual como en su sentido de responsabilidad social; por lo que se han emitido también sentencias acerca de que la protección de ese derecho no pueden implementarse medidas regresivas. También ha planteado la necesidad de contar con políticas públicas adecuadas en materia de servicios salud con establecimientos en condiciones sanitarias adecuadas.

En la Observación General número 14, el Comité de Derechos Económicos, Sociales y 
Culturales de la Organización de las Naciones Unidas dispone que el derecho a la salud garantiza pretensiones en términos de disponibilidad, accesibilidad, no discriminación, aceptabilidad y calidad de los servicios de salud y refiere que los poderes públicos tienen obligaciones de respeto, protección y cumplimiento en relación con él; además, se prevé la aplicación progresiva aunque se reconocen los obstáculos que representa la limitación de los recursos disponibles, por lo que existe el deber concreto y constante de avanzar lo más expedita y eficazmente posible hacia su plena realización. ${ }^{2}$

La Corte Interamericana de Derechos Humanos en el Caso Ximenes Lopes Vs. Brasil determinó que la salud es un bien público cuya protección está a cargo de los Estados, por lo que éstos tienen la obligación de prevenir que terceros interfieran indebidamente en el goce de los derechos a la vida y a la integridad personal, particularmente vulnerables cuando una persona se encuentra bajo tratamiento de salud. Por lo que además consideró que los Estados tienen el deber de regular y fiscalizar toda la asistencia de salud prestada a las personas bajo su jurisdicción, como deber especial de protección a la vida y a la integridad personal, independientemente de si la entidad que presta tales servicios es de carácter público o privado. ${ }^{3}$

En el Caso Gonzales Lluy y otros Vs. Ecuador, la Corte regional retomó que de acuerdo con el artículo 10.2, inciso f) del Protocolo de San Salvador se establece que entre las medidas para garantizar el derecho a la salud, los Estados deben impulsar "la total inmunización contra las principales enfermedades infecciosas"; "la prevención y el tratamiento de las enfermedades endémicas, profesionales y de otra índole", y "la satisfacción de las necesidades de salud de los grupos de más alto riesgo y que por sus condiciones de pobreza sean más vulnerables".

Añadió que las mismas obligaciones se prevén en el artículo 12.2 del Pacto Internacional de Derechos Económicos, Sociales y Culturales y, recapituló que de acuerdo con la Observación General número 14, el derecho al más alto nivel posible de salud genera algunas obligaciones básicas y mínimas, que incluyen facilitar medicamentos esenciales, según las definiciones periódicas que figuran en el Programa de Acción sobre Medicamentos Esenciales de la OMS. ${ }^{4}$

En materia de bioética y responsabilidad médica, la Corte Interamericana explicó que la Asociación Médica Mundial en su Declaración de Lisboa sobre los derechos del paciente en 1981, que es la primera que regula de manera más general la relación médico-paciente y en concreto, los derechos de este último, inicia señalando que "aunque el médico siempre debe actuar de acuerdo a su conciencia y en el mejor interés del paciente, se deben hacer los mismos esfuerzos a fin de garantizar la autonomía y justicia con el paciente".

Así, consideró el tribunal que el principio de autonomía adquiere vital importancia en el ámbito de la salud, como una regla que instaura un balance adecuado entre la actuación médica benéfica y el poder decisorio que retiene el paciente como sujeto moral autó-

\footnotetext{
2 Observación General número 14 (2000). El derecho al disfrute del más alto nivel posible de salud (artículo 12 del Pacto Internacional de Derechos Económicos, sociales y Culturales). Comité de Derechos Económicos, Sociales y Culturales de la Organización de las Naciones Unidas. 11 de agosto de 2000. E/C. 12/2000/4.

3 Corte IDH. Caso Ximenes Lopes Vs. Brasil. Sentencia de 4 de julio de 2006. Serie C No. 149, párr. 89.

4 Corte IDH. Caso Gonzales Lluy y otros Vs. Ecuador. Excepciones Preliminares, Fondo, Reparaciones y Costas. Sentencia de 1 de septiembre de 2015. Serie C No. 298, párr. 193.
} 
nomo, a fin de no incurrir en acciones de corte paternalista en las que el paciente sea instrumentalizado para evitarle un daño en su salud. Inclusive la propia Corte Interamericana interpretó cómo debe desarrollarse el consentimiento informado en términos de la Declaración Universal sobre Bioética y Derechos Humanos de la UNESCO. ${ }^{5}$

De esta forma, puede entenderse que el derecho a la salud es un bien valioso conectado con otros derechos fundamentales, a partir de los principios de indivisibilidad e interdependencia; por ello, los Estados deben desarrollar todas las acciones positivas para protegerlo en clave progresiva (sin regresar a medidas de menor tutela) y propiciando el más alto nivel de protección posible, sin discriminación alguna.

Desde esta óptica, en casos de conflicto del derecho a la salud, el tribunal debe decidir desde principios y razonabilidad, para evitar con sus decisiones la polarización social. Esos principios sirven de guía para su actuación, en la medida en que conforman un parámetro lo suficientemente aceptable y puede ponderarlos abierta y pluralmente. La Declaración Universal sobre Bioética y Derechos Humanos de la UNESCO en sus artículos 3 a 17 prevee varios de esos principios éticos susceptibles de ponderación, entre los cuales se encuentran los siguientes: dignidad humana, beneficios y efectos nocivos, autonomía, consentimiento, vulnerabilidad, privacidad, igualdad, justicia, equidad, acceso a la ciencia y protección del medio ambiente, etcétera.

En el escenario de la pandemia del COVID-19 y, frente a un supuesto caso de reclamo judicializado surgido por escasez de recursos, por ejemplo, ante la potencial falta de respiradores para dar acceso a la protección de la salud, en sede judicial se deben tomar en cuenta necesariamente, al menos, los siguientes principios:

* Dignidad humana, para no degradar ni inhumanizar a la persona.

* Maleficiencia y beneficiencia, para no dañar a alguien y, prevenirle el daño.

* Autonomía, para respetar la elección y preferencia de la persona.

* Vulnerabilidad, para proteger a los grupos vulnerables.

* Igualdad y no discriminación, trato igual con miras a la justicia y trato diferenciado cuando existan condiciones para tal efecto.

* Solidaridad y cooperación, para preocuparse desde lo colectivo.

* Progresividad, para recibir el más alto nivel de salud, sin medidas regresivas.

* Protección y sustentabilidad, para el beneficio futuro y a terceros de los recursos hospitalarios.

Debe recordarse, con Beauchamp y Childress, el hecho de que esos principios no son absolutos; sino que deben armonizarse o ponderarse en cada caso; para lo cual sirve de guía el principio de trato diferenciado que permite tratar a una persona de manera distinta en el acceso a la salud, cuando se puede presumir racionalmente que el perjudicado consentiría si pudiera decidir en circunstancias de imparcialidad, por ejemplo a sabiendas de que alguien tiene un mejor pronóstico que el suyo, pues de acuerdo con la regla maximin de Rawls, el principio de cooperación apuesta por obtener lo mejor en la peor situación.

De esta manera, se respeta el principio de no discriminación, en caso de tener que decidir qué personas deben tener preferencia de acceso a los servicios de salud en el caso

5 Corte IDH. Caso I.V. Vs. Bolivia. Excepciones Preliminares, Fondo, Reparaciones y Costas. Sentencia de 30 de noviembre de 2016. Serie C No. 329, párrs. 160 y 182 . 
de desabasto de respiradores, en virtud de que se justifica la asignación y distribución de recursos escasos cuando ello suceda en beneficio de las personas más vulnerables o en menor ventaja que otras, salvo en la extrema situación de que la situación de los más aventajados pueda ayudar a mejorar la de los más necesitados o vulnerables. Esos principios pueden acompañarse de otras directrices que son una versión humanista de la igualdad progresiva y las virtudes judiciales:

* Equidad: Principio aristótelico que contextualiza en sentido evolutivo la aplicación de la regla de justicia. Se procura el trato igual a las personas, salvo que se actualice alguna diferencia relevante que lo justifique.

* Perspectiva de género: Busca equilibrar las relaciones de poder entre hombre y mujer, para reivindicar las libertades de la mujer; por lo que apuesta por una erradicación de las condiciones estructurales que impiden la igualdad sustantiva.

* Principio de interseccionalidad y enfoque diferencial: Impone la necesidad de advertir los múltiples e interseccionales efectos de la discriminación y, dar un trato diferente y especializado a quienes se encuentren en mayor estado de vulnerabilidad.

* Compasión: Concilia la preocupación de eliminar daños, en clave de progresividad de atención a los grupos más vulnerables.

* Transparencia y rendición de cuentas: Permite, desde el derecho de acceso a la información, una vigilancia y escrutinio de las decisiones públicas que son de interés colectivo.

* Reciprocidad y universalidad: Procura compartir el aprovechamiento de recursos desde el beneficio social idóneo y, en esa misma medida, hacer funcionar una regla de trato igual para casos que compartan las propiedades constitutivas relevantes.

* Razonabilidad y proporcionalidad: Los medios para conseguir un fin debe reportar un beneficio mayor en el disfrute de los derechos de una persona o colectivo que el sacrificio que causan sobre tal disfrute en la otra persona o colectivo.

* Coherencia sistémica: La decisión adoptada debe armonizarse con los materiales jurídicos disponibles, donde haya prevalencia de principios por encima de las reglas, para reflejar una confianza consistente con los fines que persigue el derecho, como es la protección general de la salud con preferencia de los menos favorecidos.

\section{Dilemas e interrogantes giratorias sobre el COVID-19}

Bajo todo el marco abordado, los dilemas morales para enfrentar la pandemia son atravesados por la escasez de recursos en el acceso al derecho de protección de la salud. Para tal efecto, a modo reflexivo, se plantean algunos casos judicializables, donde las respuestas ofrecidas son una oportunidad de mantener en constante diálogo las inquietudes de cara al futuro.

Imaginemos tres escenarios. Todos comparten lo siguiente: personas contagiadas por COVID-19, sector de salud público, desabasto de ventiladores artificiales y prioridad de atención. En el primero, la escasez hace enfrentarse a un joven de 25 años con una mujer embarazada. El segundo supuesto se presenta entre un joven de 20 años sin estudios y un adulto mayor de 75 años que es cientifíco de una universidad, presidente de una fundación de apoyo al cáncer de la niñez y que apoya otras acciones filantrópicas. En el tercer caso se enfrenta una persona (podría ser un familiar nuestro) con un médico. ¿Qué criterios éticos y jurídicos deberá tomar en cuenta el tribunal, frente a los que tuvo 
el personal médico, para resolver la preferencia prioritaria en la colocación del respirador artificial?

Desde la idea de lo "segundo mejor" con extensión a los campos de las buenas pasiones, el principio de imparcialidad, la racionalidad argumentativa y los principios de acceso diferenciado a la protección de la salud, todo parece apuntar a que el tribunal debe tener en cuenta los siguientes factores concretos, según cada caso.

Caso del joven y la mujer embarazada. Tendría orden de preferencia la mujer embarazada, al tratarse de una persona con un mayor rango de vulnerabilidad. En efecto, en el preámbulo de la Declaración Universal sobre Bioética y Derechos Humanos de la UNESCO expresamente se indica: Reconociendo que una manera importante de evaluar las realidades sociales y lograr la equidad es prestando atención a la situación de la mujer. Lo cual denota una intención de proteger en forma robusta, desde la diferencia y la perspectiva de género, a aquellas mujeres que se encuentren en especial situación de riesgo o deventaja por su realidad social.

También es importante lo previsto en los artículos 2, inciso c), 4.2 y 12 de la Convención sobre la Eliminación de todas las formas de Discriminación contra la Mujer establecen que los Estados deben adoptar las medidas de protección jurídica para garantizar los derechos de la mujer sobre una base de igualdad; asimismo, establece que se deben adoptar medidas de carácter especial, con énfasis a proteger la maternidad, las cuales no serán consideradas discriminatorias y, finalmente, se ordena que se adopten todas las medidas necesarias para eliminar la discriminación contra la mujer en la esfera de la atención médica, para la igualdad en el acceso a los servicios de atención médica respectivos; con especial referencia a los casos de parto o embarazo.

Asimismo, en el artículo 10.2, inciso f) del Protocolo de San Salvador en materia de Derechos Económicos, Sociales y Culturales, se observa la orden de que la satisfacción de las necesidades de salud, en orden de preferencia, debe hacerse por los grupos de más alto riesgo y que por sus condiciones de pobreza sean más vulnerables; lo cual es coherente con el principio de diferencia desde la imparcialidad rawlsiana.

Otro factor importante es que las mujeres se han visto mayormente afectadas por la crisis sanitaria, tanto por violencia doméstica como por exposición al contagio en el área médica en que predominante se desarrollan como cuidadoras o enfermeras. En la resolución 1/2020, Pandemias y derechos humanos en las Américas, la Comisión Interamericana de Derechos Humanos diagnosticó que por lo general los cuidados de las personas enfermas o necesitadas de especial atención recaen fundamentalmente en las mujeres, a expensas de su desarrollo personal o laboral, existiendo un escaso nivel de institucionalización y reconocimiento social para las tareas de cuidado; asimismo, subrayó la necesidad de ofrecer una atención diferenciada a las mujeres profesionales de la salud que trabajan en la primera línea de respuesta a la crisis sanitaria del COVID-19.

Por lo que, el conjunto de factores muestran, incluso desde el principio de interseccionalidad y enfoque diferencial especializado, la necesidad de priorizar la protección de la mujer embarazada que se encuentra en una situación de mayor vulnerabilidad y, por lo tanto, dado el estado transicional de salud que atraviesa, la persona que se encuentra en mejor situación, como sería el joven del caso, debe ceder su posición de preferencia para quien se encuentra un escenario peor reciba la atención médica. 
Caso del joven sin estudios y el señor de 75 universitario. Tendrá orden de preferencia el joven por encima del señor adulto mayor, puesto que de acuerdo con los principios de beneficiencia, cooperación, sustentabilidad y principio de trato diferenciado; se puede presumir, en sentido racional que en circunstancias de imparcialidad y, no de egoísmo individual, la persona misma podría elegir a quien tiene un mejor diagnóstico en cantidad y calidad de vida.

La Comisión Interamericana en su resolución 1/2020 ha establecido la prohibición de limitar el acceso a los recursos y tratamientos médicos sustentados en la edad de las personas mayores de edad, pero ello en modo alguno impide que exista un balance para resolver dilemas de casos concretos, siempre que el factor de la edad no sea el detonante de la justificación para tomar la decisión.

En ese sentido, la Comisión también considera como grupo vulnerable a niñas, niños y adolescentes, al exigir su protección reforzada desde el interés superior de la infancia, donde se debe poner cuidado especial en aquellos casos que las condiciones económicas y sociales sean relevantes, para hacer un trato diferenciado.

Para resolver la cuestión, se debe tomar en cuenta aquellas situaciones de las personas que estuvieron fuera de su control, para responsabilizarse o no, de ellas. De modo que una sociedad justa pueda minimizar aquello que es ajeno al control de la persona y, solo dar importancia a las que estuvieron en su completo manejo y voluntad, ya que muchas de las ocasiones, de los contextos depende la disposición de recursos suficientes para el desarrollo de una persona.

Solo a modo de ejemplo, Rodolfo Vázquez nos recuerda que ese tipo de casos no son nuevos en teoría de la justicia, al respecto retoma a Dworkin quien planteó el caso de dos personas dotadas con iguales talentos y recurso naturales, una de las que trabajó con esfuerzo, esmero y ambición, para incrementar su dotación inicial, mientras que la otra prefierió no esforzarse y consumir sus dotaciones hasta colocarse en situación de desventaja. La gran pregunta que se detona es por qué la sociedad debería hacerse cargo de la irresponsabilidad del dilapidador e inclusive, asumir el pago (por ejemplo de un seguro de desempleo) $y$, transferirle al irresponsable parte de las ganancias producidas por el esforzado (Vázquez, 2019: 165 y 166).

De vuelta al caso, debe considerarse que México cuenta con datos alarmantes de deserción escolar y falta de oportunidades de acceso a la educación para los adolescentes, motivados generalmente por situaciones de pobreza, marginación y precaridad en el acceso a los servicios.

Por ejemplo, en su Informe Anual 2017, UNICEF reportó que la permanencia en la escuela es el primer reto que enfrentan los adolescentes en México. Más del $40 \%$ de jovenes en nuestro país no asiste a la escuela, la gran mayoría abandona los estudios al terminar la secundaria. 3 de cada 10 jovenes entre 15 y 17 años de edad está fuera de la escuela por ayudar económicamente a sus familias. Además, 4 de cada 10 adolescentes en situación de pobreza son los que pueden continuar estudiando después de la secundaria; entre lo que se detectó también fue el creciente número de mujeres en embarazo temprano y la propensión a encontrarse unidas informalmente en pareja, lo que afecta negativamente la permanencia escolar; por lo que una forma compensatoria de equilibrar las eventua- 
lidades azarosas es dar una dotación adicional a la persona en desventaja, para acceder a ciertos servicios.

Recuérdese además que conforme al principio de interseccionalidad y de enfoque diferencial especializado, los grados de discriminación pueden ser mucho más arraigados o profundos, conforme aumenten la serie de características para la situación de vulnerabilidad o marginación. Por ejemplo, se puede ser pobre, pero blanco y de religión mayoritaria; en contrapartida, alguien puede ser pobre, índigena, mujer y, en la etapa de vejez. De suerte que dicho principio lo que procura es entender la profundidad e intensidad de la situación de vulnerabilidad, para descifrar cómo desde lo estructural es conveniente más una acción que otra.

Acá no aplica estrictamente el tema de la adolescencia porque se trata de un adulto joven (20 años) y, otro varon de 75 años (adulto mayor). Sin embargo aunque ambos comparten las características de hombre con capacidades potenciales, hay diferencias de grado que los colocan en situaciones diferentes. Uno de ellos, ha desarrollado sus capacidades y, eso le concede ciertos privilegios por encima del otro. En efecto, el adulto mayor tiene estudios univesitarios, probablemente de posgrado y se dedica a la ciencia, por lo que tiene acceso a ciertos satisfactores a través de su entorno laboral y, además, cuenta con cierta capacidad económica superior al grueso de la población, al dedicarse a actividades solidarias de filantropía.

En el otro lado, se tiene a una persona que podría encontrarse, cuando atravesó su etapa adolescente, en el porcentaje de personas que no pudieron permanecer en la escuela por diversos motivos, ya que al menos en esa escala se encuentran 4 de cada 10 jóvenes $y$, eso bien pudo colocarle en el escenario precariedad que influyó en su actual circunstancia, sin que pudiera controlar tales factores; o bien, encontrar redes de apoyo públicas para superarlos.

Otro elemento importante surgido de los principios de la vulnerabilidad, cooperación, solidaridad, dignidad humana y sustentabilidad radica en analizar que en las condiciones eutanásicas, indica Gascón, las situaciones de indignidad irreversible se pueden manifestar en el riesgo considerable de muerte próxima, por lo que en ese tipo de casos, se debe dignificar a la persona a través de la limitación del esfuerzo terapéutico (Gascón, 2003: 5-12), por lo que en unión con el principio de trato diferenciado, desde la imparcialidad ralwsiana, se presume que cualquiera de los involucrados, preferirá a aquel que tuviera el mejor diagnóstico de vida.

En tal virtud, las diferencias de privilegio de uno, frente a las circunstancias de desventaja del otro, sin fundarse en el razonamiento en la edad, deben orientarse a que se brinde el respirador a quien tiene mayores ventajas de sobrevivencia sin riesgo de muerte próxima; lo que en términos generales, puede suceder la mayor de las ocasiones en una etapa más joven que otra. Por lo que además, deberá considerarse si en el adulto mayor existen factores de cormobilidad que signifique, en forma adicional, una razón suficiente para situar a la persona en un diagnóstico mayor de muerte próxima.

En la Guía Bioética para la Asignación de Recursos Limitados de Medicina Crítica en Situación de Emergencia emitida por el Consejo de Salubridad General en México, con motivo del COVID-19; se establece que, entre los criterios para dicha asignación de recursos 
escasos, el personal médico debe indicar el puntaje de priorización de cada paciente y evaluar de manera periódica la situación; ante la indicación específica de que el servicio de ventilador artificial es temporal $y$, por tanto, dar preferencia a quienes tienen una mayor probabilidad de sobrevivir con ayuda de la medicina crítica. Información con la cual, en caso de que sea el joven que se encuentre en peores condiciones de sobrevivencia, entonces, no habría ostáculo para dar preferencia al adulto mayor.

Caso de una persona (que puede ser un familiar) frente a personal médico. El principio de diferencia, ante casos de extrema situación, permite que se dé preferencia a los más aventajados cuando estos puedan ayudar a mejorar la situación de los más necesitados o vulnerables. La Comisión Interamericana en su resolución 1/2020 ha puesto énfasis en la necesidad de garantizar la continuidad de los servicios médicos y ha determinado que se deben movilizar el máximo de recursos disponibles, para hacer efectivo el derecho a la salud.

Una visión caleidoscópica nos orienta a entender que la presencia del personal médico es necesaria y no caben las codicias egoístas porque de ellos depende hacer operativos los principios de maleficiencia y beneficiencia; es decir, en ellos recae la posibilidad de no causar daños a otros y maximizar los beneficios para disminuir los daños posibles.

Un ejercicio cooperativo, solidario y de sociabilidad comprende que la salud es un bien colectivo que pasa antes, para su individualización, por las manos de los expertos, cuya presencia es imprescindible para conseguir el fin pretendido de maximizar la salud colectiva. Además, una posición de equidad, justicia y compasión permite darse cuenta de que ellos, por cuestiones ajenas a su control voluntario, son quienes se encuentran expuestos en mayor medida al contagio del virus, debido a la fraternidad manifiesta con la comunidad, para solidarizarse con la causa; por lo que en reciprocidad, su actuar desinteresado les coloca en orden de prioridad preferente para la atención de su salud.

Lo cual está auspiciado también en la regla maximin, al procurar que el mejor escenario de atención de la salud colectiva sea posible, cuando los encargados de hacerlo, se encuentren en óptimas condiciones de ofrecer sus servicios médicos, en las mejores condiciones posibles porque de otro modo encontrarían un desincentivo en continuar coayuvando en su labor. De ese modo también, se cumple con el principio de proporcionalidad porque se permite reportar un beneficio mayor en el disfrute de los derechos del colectivo que el sacrificio que causaría sobre tal disfrute en otras personas.

Los casos expuestos son un simple recorrido del diálogo bioético que debe permanecer abierto para escenarios futuros y compartirse entre la comunidad internacional para el intercambio de experiencias exitosas con enfoque de derechos humanos, como lo establece la Comisión Interamericana en la resolución 1/2020 y servir también de parangón para las decisiones de los tribunales en armonía orientativa con lo que discutan los Comités de Bioética.

A propósito de lo anterior, de acuerdo con la Guía Bioética para la Asignación de Recursos Limitados de Medicina Crítica en Situación de Emergencia emitida por el Consejo de Salubridad General en México, se obligó que en cada institución pública hospitalaria, se establecieran Comités Hospitalarios de Bioética para la toma de decisiones de triaje en la citada situación de emergencia sanitaria causada por el COVID-19. El Comité se confor- 
ma por un primer responsable en medicina espcialista en terapia intensiva, medicina de urgencias, neumología, medicina interna o afín; un segundo médico responsable en las mismas áreas y el administrador de la unidad hospitalaria; los dos últimos apoyan con información y soporte técnico al primero, para la toma de decisiones.

Las decisiones del sistema de triaje tienen previstas al menos dos decisiones: la inicial y la posterior, derivada de una reevaluación. En ellas se determina el tratamiento médico y la asignación de recursos de acuerdo a un sistema de puntaje sobre la probabilidad de supervivencia tras la evaluación acuciosa del paciente (impacto de la infección, cormobilidad, expectativa del tratamiento, situación específica y de vulnerabilidad, etcétera).

Las decisiones pueden ser apeladas, sea para rectificar el puntaje (permitidas); o bien, para cuestionar el sistema de priorización (no permitidas). El Comité Revisor de Triaje resolverá lo conducente, considerando la situación especial de pacientes o familiares que tengan discapacidad o pertenezcan a algún grupo étnico. La finalidad específica del sistema de Triaje en la asignación de recursos escasos consiste en salvar la mayor cantidad de vidas en función de quienes tienen la mayor probabilidad de sobrevivir priorizando la ayuda de la medicina crítica.

En concomitancia, debe señalarse que en México no existen tribunales especializados en materia de protección de la salud; sin embargo, a través del juicio de amparo se pueden cuestionar decisiones públicas cuando la asignación de recursos para la protección de ese derecho, se considere inadecuada. Se trata de un mecanismo de protección constitucional de tramitación sumaria que puede emitir resoluciones urgentes, con la finalidad de tutelar de forma anticipada el derecho defendido, a través de medidas cautelares, como lo es la suspensión restitutiva de derechos. De modo que, las decisiones que se emitan a través del Comité Revisor de Triaje, producto de la apelación interpuesta contra decisiones del Comité Hospitalario de Bioética, puede ser revisable en el marco jurisdiccional del control concentrado de constitucionalidad, en caso de que no exista algún obstáculo procesal en el camino.

La relevencia de este mecanismo escalonado de control de las decisiones en materia de bioética, donde converge información y racionalidad entre los Comités de Bioética y los tribunales judiciales, radica en que hay una retroalimentación dialógica con enfoque crítico, para evaluar hermenéuticamente cada uno de los casos que se presentan y, de ellos, a través de la concreción de los principios bioéticos, unidos a las virtudes judiciales, pueden irse produciendo reglas específicas para futuros casos con propiedas constitutivas análogas.

De suerte que el diálogo médico-científico con el discurso judicial, se enriquece desde los parámetros bioéticos que concilian buscando una misma directriz, tal como lo propone Carlos Nino, resolver a través de lo "segundo mejor" y así proyectarlo en el derecho de protección de la salud, cuando la escasez de recursos apremie necesidades urgentes y diferencias relevantes en la atención de las personas por COVID-19 y, de esa manera, hacer que las decisiones de los Comités de Bioética y de los tribunales se imbrinquen e integren recíprocamente con decisiones que al futuro, a través de la jurisprudencia o ratio decidendi, serán constitutivas del orden constitucional en materia de protección del derecho a la salud, en clave de progresividad. 
Un esquema que aunque no es novedoso bien la vale la pena reproducir, tal como lo ha hecho el sistema interamericano a través de la Corte que se ha enriquecido fruto del diálogo abierto que sobre bioética ha establecido con toma de conocimiento de los materiales jurídicos y asociaciones que sobre esa materia se han pronunciado, para avanzar y evolucionar críticamente en la protección de la salud, como bien colectivo de interés social, desde el principio pro persona que busca favorecer en la mayor medida posible la tutela de los derechos humanos.

\section{Emociones virtuosas}

Los casos de muestra, bien pueden apoyarse en la imparcialidad propuesta y las directrices aludidas, sin embargo, también será necesario que los tribunales al pronunciarse, lo hagan con base en diversas virtudes y buenas pasiones, en el sentido que lo defienden MacCormick y Atienza, las cuales pueden concretarse de la siguiente forma:

* Objetividad y valentía: El tribunal debe actuar con serenidad y equilibrio reflexivo, cuestionando incluso cualquier prejuicio que contamine su decisión y, a la vez debe procurar que su actuación defienda en clave de progresividad, indivisibilidad e interdependencia, el disfrute del derecho a la salud.

* Profesionalismo y compasión: El tribunal debe atender el caso con profundo conocimiento de las tensiones teóricas y filosóficas que rodean el problema, propiciando un diálogo bioético transdisciplinario y, evitar que su decisión replique efectos opresivos sobre los grupos menos privilegiados (que han sido quienes quedaron mayormente expuestos en la pandemia debido al ámbito informal laboral o los ingresos precarios, como se establece en la resolución 1/2020).

* Excelencia humanista y perspicacia: El tribunal debe ser consciente de que su decisión afectará en lo individual y colectivo a un grupo de personas con intereses y preferencias; por lo que deberá resolver cada problema con agudeza, para lograr primero un empoderamiento de los menos aventajados y, luego, excepcionalmente, cuando se hayan corregido las deficiencias estructurales de mayor importancia, podrá hacerse un cambio paulatino en los parámetros de prioridad en la atención médica.

* Excelencia responsable, con fortaleza y altura de miras: El tribunal debe asumir que la consecuencia de su decisión posiblemente encuentre resistencias o desacuerdos; por ello, resulta de primera importancia que la confianza de imparcialidad se logre mediante una argumentación jurídica sólida, correcta, persuasiva y transparente, ya que esa decisión será parte constitutiva del orden constitucional hacia el futuro.

\section{Conclusiones}

El modelo de equilibrio reflexivo propuesto no se finca en decidir sobre todo o nada desde las principales corrientes éticas; sino que busca un despliegue de razones justificadas para evitar el utilitarismo radical, pero sin dejar de observar por completo las consecuencias y las condiciones de lo posible. Por ello, los tribunales pueden auxiliarse en un marco de virtudes desde la ética mínima acompañadas de una comprensión de la teoría de las buenas pasiones y propiciando un diálogo abierto con los Comités de Bioética para la mutua retroalimentación hacia el futuro.

Aún en la convicción de lo "segundo mejor" es inevitable que cualquier decisión deje heridas abiertas de lo que pudo ser. Una sensación entre memoria, culpa y justicia. Una 
mezcla moral de transpolación hacia el derecho. Detrás de todo se esconde una profundad reflexión que en sentido metafórico podemos asociar a la historia de Hanna Schmitz cuando interpela al juez y le pregunta ¿Y usted qué hubiera hecho?

La expresión surge del libro "El lector" escrito por Bernhard Schlink, desarrollada en el plano de la época del nazismo alemán, donde la protagónista Hanna Schmitz es acusada de haber permitido que murieran más de trescientas mujeres judías encerradas en una iglesia que había sido bombardeada durante una de las marchas de la muerte del campo de concentración a su cargo. En el relato destaca por qué Hanna no se cuestionó por qué hizo lo que hizo; ni entiendía por qué se le reclamaba que no había abierto las puertas de la iglesia, pues ella de forma indignada preguntó ¿Qué hubiera sucedido, si al falicitarles la salida, huían dispersándose por el campo? Después, cuando el juez la cuestionó por lo sucedido, ella le espeta la pregunta ¿Y usted qué hubiera hecho? (Ruiz, Douglas y Cárcova, 2014: 9).

La fría frase, en el marco de la pandemia, nos da la posibilidad de sentir empatía en el esfuerzo de racionalidad universal donde los tribunales buscan encontrar una respuesta correcta, como ideal regulativo de los casos díficiles o trágicos, pero sobre todo, quiere alejarse de la cómplice frivolidad, para reivindicar el valor social del diálogo colectivo de las decisiones públicas que ante la escasez de recursos ven cómo las limitadas opciones de proteger el derecho a la salud, deben convocar más al encuentro que al desencuentro y frustación que causa la muerte y la desesperación. Un escrutinio más franco con los tribunales, también es aliciente de confianza en una justicia humanista, progresista e igualitaria.

En el esfuerzo de enfrentar el necroderecho desde la descomplicidad, propone Narváez, el operador jurídico debe trabajar con una ética hermenéutica de la emergencia, donde después de la catársis que implica aceptar la complicidad, debe distanciarse de la inercia normativista que le impone el ambiente propio de la judicatura formalista y buscar formas creativas con las que se elimine la posibilidad de poner en riesgo a otros seres humanos (Narváez, 2017: 111). De este modo, el tribunal puede aproximarse con una visión constitucionalista, pero crítica desde lo social, al buscar crear las mejores condiciones posibles dentro de las peores circunstancias existentes.

En cualquier caso, la mirada retrospectiva que convoca al tribunal desde las virtudes y las buenas pasiones, parte de un ejercicio de prudencia, para que en ese ejercicio de equilibrio reflexivo una ida y vuelta del presente al pasado le permita evaluar los méritos de la decisión y, aprender lo que se puede hacer mejor hacia el futuro. 


\section{REFERENCIAS BIBLIOGRÁFICAS}

- ATIENZA, Manuel. (1999). “Juridificar la bioética”. En VÁZQUEZ, Rodolfo. Bioética y derecho. México: FCE-ITAM.

- ATIENZA, Manuel. (2012). Tras la justicia. Madrid: Ariel.

- BEAUCHAM, Tom y CHILDRESS, James. (1979). Principles of biomedical ethics. Oxford: Oxford University Press.

- CORTINA, Adela. (2010). Ética mínima. Introducción a la filosofía práctica. Madrid: Tecnos.

- GASCÓN, Marina (2003). “De qué estamos hablando cuando hablamos de eutanasia.

Humanitas. Humanidades Médicas, vol. 1, núm. 1, 5-12.

- NARVAÉZ, José Ramón. (2017). Necroderecho. México: Libitum.

- NINO, Carlos. (1980). Fundamentos de derecho constitucional. Buenos Aires: Astrea.

- RAWLS, John. (2004). Teoría de la justicia. México: FCE.

- RUIZ, Alicia, DOUGLAS, Jorge y CÁRCOVA, Carlos. (2014). La letra y la ley. Estudios sobre derecho y literatura. Buenos Aires: Infojus.

- VÁZQUEZ, Rodolfo. (2019). Teorías contemporáneas de la justicia. Introducción y notas críticas. México: IIJ.UNAM.

\section{REFERENCIAS JURISPRUDENCIALES}

- Jurisprudencia de la Suprema Corte de Justicia de la Nación de México.

- CIDH, Resolución 1-2020, Pandemias y derechos humanos en las Américas. Resolución 10 de abril de 2020.

- Corte IDH. Caso Gonzales Lluy y otros Vs. Ecuador. Excepciones Preliminares, Fondo, Reparaciones y Costas. Sentencia de 1 de septiembre de 2015. Serie C No. 298.

- Corte IDH. Caso I.V. Vs. Bolivia. Excepciones Preliminares, Fondo, Reparaciones y Costas. Sentencia de 30 de noviembre de 2016. Serie C No. 329.

- Corte IDH. Caso Ximenes Lopes Vs. Brasil. Sentencia de 4 de julio de 2006. Serie C No. 149.

- Observación General número 14 (2000). El derecho al disfrute del más alto nivel posible de salud (artículo 12 del Pacto Internacional de Derechos Económicos, sociales y Culturales). Comité de Derechos Económicos, Sociales y Culturales de la Organización de las Naciones Unidas. 11 de agosto de 2000. E/C. 12/2000/4. 